$11-9-2018$

\title{
Constructing the First Year Experience: Improving Retention and Graduation Rates at a Hispanic-Serving Institution
}

\author{
Sonia M. Gipson Rankin \\ University of New Mexico - School of Law \\ Tim Schroeder \\ University of New Mexico - School of Law \\ Joe Suilmann \\ University of New Mexico - School of Law \\ Pamela Cheek \\ University of New Mexico - School of Law
}

Follow this and additional works at: https://digitalrepository.unm.edu/law_facultyscholarship

Part of the Curriculum and Social Inquiry Commons, Educational Assessment, Evaluation, and Research Commons, Higher Education Commons, and the Legal Education Commons

\section{Recommended Citation}

Sonia M. Gipson Rankin, Tim Schroeder, Joe Suilmann \& Pamela Cheek, Constructing the First Year Experience: Improving Retention and Graduation Rates at a Hispanic-Serving Institution, Reinvention Collaborative RC20/20 Higher Education Conference 1 (2018).

Available at: https://digitalrepository.unm.edu/law_facultyscholarship/664

This Presentation is brought to you for free and open access by the UNM School of Law at UNM Digital Repository. It has been accepted for inclusion in Faculty Scholarship by an authorized administrator of UNM Digital Repository. For more information, please contact amywinter@unm.edu, Isloane@salud.unm.edu,

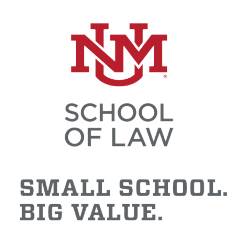

BIG VALUE. 


\section{Constructing the First Year Experience: Improving Retention and Graduation Rates at a Hispanic-Serving Institution}

University of New Mexico

November 9, 2018, 3:00-4:15 PM

Breakout Session 2C

In 2012, UNM teamed up with the Gardner Institute for Excellence in Undergraduate Education, to conduct a Foundations of Excellence ${ }^{\circledR}$ (FoE) First College Year Self Study (2012-13) addressing student success. Working with consultant George Kuh, UNM examined new student orientation, curriculum, advising services, time-to-degree, and fixes to UNM's organizational "silos." The self-study process resulted in a report and action plan, which UNM began to implement the following year (AY 2013-14) with a focus on improving its first-year experience.

Several factors militated for a first-year focus. Approximately 30 percent of UNM students enter with one or more remedial needs in math, reading, or composition while students with "national merit" designation also matriculate with each freshman class. Between the 2009 and 2010 cohorts, retention to the third semester had dropped to 74 percent. Further, over 23 percent of all student stop outs were occurring before the third term. The four-year rate was hovering near 15 percent, and the six-year rate was around 47 percent. UNM is a complex institution: a Carnegie classified Research One university, a public doctorate-granting flagship, one of a small but growing number of Hispanic Serving Institutions in the U.S, and a school with a majority minority student population. UNM admits high numbers of Pell-eligible students, firstgeneration college students, and students who come from homes in which English is a second language. This wide range of student characteristics and levels of readiness requires an equally wide range of approaches in providing a challenging and supportive academic experience for all students.

The Vice Provost for Teaching, Learning, and Innovation at the time, Greg Heileman, and the Dean of University College and Honors College, Kate Krause, assembled a First Year Steering Committee (FYSC) to implement recommendations and meet two goals: improve retention to the third semester by 80 percent and six-year graduation rates by 50 percent by the second quarter of 2015.

The impact on student success was dramatic. Numbers for Spring 2018 show that the four-year graduation rate has reached 32.5 percent (the final rate is expected to top 34 percent). The rate has more than doubled in six years. The six-year graduation rate also improved steadily, over the same time period, increasing from a little over 45.7 percent to 48.8 percent in 2017.

After the third-semester retention rate dropped to 74 percent in 2011 , it climbed steadily through 2015, with a slight drop again in 2016. Retention of Hispanic students reached an all-time high of 80.1 percent in 2014 , and the overall retention rate for full-time beginning freshmen eclipsed 80 percent in 2015, meeting the UNM2020 third-semester retention goal. 2016 third-semester retention rates are expected to dip again, owing possibly to greater numbers of non-resident students and improved regional employment opportunities.

As members of the First Year Steering Committee, the team of presenters here directed, invented, coordinated, measured, and documented programs for linking students to the academic experiences and support that were best attuned to their needs. Dr. Greg Heileman and Dr. Chaouki Abdallah are delivering findings in a parallel panel at the Reinvention Collaborative on the degree mapping techniques developed and implemented to support UNM's 
time to graduation initiative. UNM's success can be traced to collaborators' willingness to design multiple pilots in different areas, assess their impact, and then, on that basis, either generalize or discard programs. A creative and energetic group of collaborators worked with leaders across institutional units to deploy multiple high engagement practices simultaneously.

\section{Multiple High Impact Practices Across the Institution}

FYSC focused on six overarching areas:

1. Student transitions to UNM

2. First-year curriculum

3. Student support

4. Faculty, staff, and graduate teaching assistant support

5. Out-of-classroom experiences

6. Data and assessment

\section{Student Transitions to UNM}

The first area, student transitions, included goals to improve communication with first-year students, redesign New Student Orientation, and improve student placement. The groups involved with the redesign brought a spirit of innovation to student transitions, experimenting with different models to best address the needs and interests of both under-prepared and wellprepared incoming students.

\section{Communication}

The Enrollment Management Division effort focused communication to first-year students around critical issues at key times, targeting support for timely registration, maintaining financial aid, and progress toward degree. The communication is supported by collection and analysis of data related to registration, financial aid, probation, and GPA. Interventions included userfriendly websites, phone calls, emails, and advising referrals.

\section{New Student Orientation}

A New Student Orientation (NSO) program redesigned in 2014 includes a greater emphasis on academic expectations, incorporates more technology into sessions, and includes more faculty participation. A comprehensive assessment process has helped the team make additional changes during annual reviews, including a better integration of advising, student support resources, and UNM's shared learning experience.

\section{Placement}

Early FYSC improvements to placement included tweaks to the ACT and SAT cut-off scores and test timing.. Beginning in 2014, students could challenge their placement by taking the COMPASS and, through improvements made in 2017, free of charge ACCUPLACER exams are available to enable rapid placement up to three times prior to the start of the semester.

\section{First-Year Curriculum}

A central recommendation of the Foundations of Excellence project was to ensure that every incoming student has access to at least one high impact practice (HIP) in the first year.

Changes to first-year curriculum, area two, included overhauls of developmental education (pedagogy that is considered below college level), introductory courses (the first courses that students encounter in a discipline), and the creation or expansion of other first-year programming. 


\section{End of Remediation}

Prior to 2014, UNM offered remedial courses, called Introductory Studies (IS) courses, in math, English, and reading. These non-credit-bearing courses were taught by faculty from Central New Mexico Community College (CNMCC), and enrollment was determined by students' incoming placement scores. Students placed into remedial courses were delayed in their progress toward a degree and separated from their peers. Working with the English and Math departments and University College, FYSC replaced all remedial courses with new transitional gateway courses for UNM students.

\section{The Math Learning Lab (MaLL)}

Intermediate Algebra is the first class for many UNM students, taken by roughly 2500 students per year. Before 2012, fewer than 35 percent of students passed Intermediate Algebra with a C or better. The three-credit sink-or-swim course yielded high fail rates among students who struggled with certain math concepts but not necessarily with others. The Mathematics and Statistics Department piloted and implemented Intermediate Algebra (formerly Math 120, now Math 101-102-103) through an emporium model. In the emporium, or "flipped classroom" model, students spend course time working on math problems with in-class support and at their own pace. They progress through the course by demonstrating successive mastery of topics in onecredit modules. After the redesign, a struggling student may, for example, earn two credits and have to retry the third later without having to sacrifice all three credits, as would be the case in a traditionally structured course. The one-credit modules also allow for more efficient pathways, since some students only need the first two modules before moving onto the next-in-sequence three-credit course. UNM's new model eliminates in-class lectures, replacing them with a learning center, called the Math Learning Lab (MaLL), utilizing interactive software (ALEKS) and on-demand personalized assistance. The first course in the revised sequence is a credit-bearing Math Foundations course followed by Intermediate Algebra.

The results from the MaLL are auspicious. In 2014 the combined pass rate for intermediate algebra (Math 101-102-103) was 70 percent, though there was also a larger number of incompletes. By Fall 2015, MaLL faculty had ironed out the issues with incompletes while resulting in success rates that were virtually identical to 2014. The MaLL has also saved UNM nearly \$20 per student over the old model. Previously, with Intermediate Algebra (Math 120 at UNM), the average DFIW rate was around 40 percent, but with the MaLL the DFIW rate is now averaging around 15 percent. The average GPA earned is about 1 percent higher in the MaLL than it was with Math 120. Finally, for STEM students who take the next-in-sequence Math 121 class, performance in Math 121 was significantly better.

\section{Math Foundations}

The Academic Math Foundations course in math places low-scoring students in a for-credit selfpaced math course called Quantitative Reasoning (now Foundational Math), which teaches foundational skills in preparation for Math 101 (see above), with opportunities to test out at twoweeks, mid-semester, or semester-end. The new model decreases time to graduation for students who previously spent a semester in a non-credit remediation course.

The Foundational Math program implements more advanced curriculum and also uses the selfpaced computerized math program (ALEKS). This allows students to focus on the skills they most need to develop and to pass over material they have already mastered. The course integrates academic tutoring, requires students to meet at least twice with a faculty advisor, and provides students with college success strategies. 
Under the old IS-Math model, roughly 700 students spent 16 weeks in Introductory Studies Math with a pass rate of 76 percent. Under the new Math Foundations curriculum in 2016, 87 percent passed with a $\mathrm{C}$ or higher. Students moved through the course more quickly (testing out at 2-weeks or mid-semester) and were eligible to begin Math 101 during the same semester. Of the students who began in Foundational Math in 2016, 39 students received credit for Math 101, 11 for Math 102, and 3 for Math 103 that same semester. For these students, the Academic Foundations shaved an average of one semester toward the student's degree.

\section{English Stretch \& Studio}

Beginning with a 2013 pilot, UNM's English Department has experimented with alternative models for teaching introductory English (General Education Core Writing). The department developed two new programs, English Stretch and Studio, to deliver the entry-level English course while retaining its existing first-year English for well-prepared students. The first new program is a "stretch" model, for students with an ACT score below 17. Stretch extends the work of the first semester writing course over two semesters (Summer-Fall, or Fall-Spring), allowing students more time to meet college-level writing expectations. The second program relies on a "studio" model for students scoring either a 17 or 18 on their ACT. These students take first-semester writing course with accompanying support from an additional one-credit-hour course.

During the pilot, the aggregated pass rate for Summer and Fall 2013 Stretch and Studio courses was 90 percent (compared to a typical pass rate for English 101 of 81-82 percent), and 93 percent of those students who went on to English 120 passed. Stretch and Studio students' reported feeling "confident" to "extremely confident" on 16 survey items related to their levels of confidence as writers, including the ability to organize and defend their ideas in writing, revise their papers, and use grammar and punctuation to clearly express their ideas. The consensus in the department is that the model remains a significant improvement over the former one. There are plans to confirm this in Fall 2018 through analysis by the Office of Institutional Analytics.

\section{Critical Text Analysis}

In 2015, UNM replaced for Introductory Studies-Reading with a Critical Text Analysis (CTA) course that can be completed through either a 1-credit or a 3-credit model. Students in the 1credit option can take reading-intensive courses concurrently; students in the 3-credit option must pass CTA before taking reading-intensive courses. Six of the ten CTA sections are piloting a new software, the NM DELT EdReady program, which uses adaptive assessment to create a customized learning path for each student. Similar to the ALEKS software used in Math Foundations and Math 101 (above), the CTA sections using EdReady allow for a self-directed learning approach; students are free to work on their customized learning path at their own pace, with the instructor providing pacing guidelines and intervening if students fall behind. CTA includes a Peer Mentor Tutor who provides help with content in-class and also holds office hours for mentoring.

\section{First-Year Programming in University College}

In alignment with UNM's first-year curriculum goals, University College began expanding firstyear programming in 2013 when it increased the number of Freshman Learning Communities (FLCS). As of 2015, UC first-year programs serve more than 2,000 students per year (out of about 3,000 total first-year students), and the programs come in a variety of formats tailored to meet the needs of particular groups of students. 
Freshman Learning Communities (FLCs) link a General Education core course with a smallenrollment seminar. Historically, FLCs have higher retention rates and student GPAs. Transition Communities prepare students in critical thinking, problem solving, and personal and social responsibility. These courses are designed around unique cohorts, including CAMP (College Assistance Migrant Program), exploratory major, and student athletes, among others, and have demonstrated a third-semester retention rate that is four percentage points higher than the overall rate, along with evidence of a narrowing achievement gap for Black, Native American, and CAMP students.

\section{Student Support}

Drawing from greater coordination across organizational lines, the first-year effort improved coordination between curriculum design and support programs (area three) by redesigning advising, consolidating student support centers, and building a new student website.

A Student Affairs Peer Mentor Tutor (PMT) program embeds five mentors into both the Math Foundations and Critical Text Analysis courses. Faculty and PMTs work together to give students individualized attention in math and reading, as well as address other aspects of students' college transition, including preparation, organization, and stress management.

The Center for Academic Program Support (CAPS) provides peer learning facilitators that support all students in all subjects, and have similarly coordinated with first-year courses. In Foundational Math, for instance, students are required to go to CAPS workshops on time management, and note and testing taking.

\section{Advising}

In 2013, advising was restructured to lower the advisor-student ratio in the University

Advisement Center and to shift advising duties to major-specific or college-specific advisors who are embedded in the programs in which students are enrolled. The reorganization of advising reduced the high 770:1 student-advisor ratios in the University College Advisement Center. In 2013, the advising structure was reorganized toward major- or college-centric advising. The average student-advisor ratio across campus was 300:1 as of 2016, coming in below a goal of 325:1 that UNM set based on recommendations from NACADA, alongside an improved balance of ratios across campus.

\section{Faculty and Graduate Teaching Assistant Support}

A new Center for Teaching and Learning (CTL), formed in 2015, facilitates teaching enhancement for faculty, staff, and graduate students. Academic Affairs has complemented this support through establishment of more detailed teaching portfolios in faculty promotion dossiers and Quality Matters training and certification for online courses. CTL houses a Graduate Resource Center, teaching enhancement programs for faculty, and peer tutoring through CAPS, which was designated in 2017 as a Center of Excellence by the National College Learning Center Association.

\section{Teaching Certificate for Graduate Students}

In 2015, Graduate Studies partnered with CTL to sponsor a certificate in college teaching for UNM graduate students, called the "Graduate Teaching Academy certificate," with dual aims in improving the quality of teaching in Teaching Assistant-led courses, and preparing UNM graduate students to enter the workforce and find placement as faculty and lecturers at colleges and universities. 


\section{Scholarship of teaching and learning}

In 2014, the CTL began the UNM Teaching Fellows Program. The program provides

opportunities to discuss teaching in an informed and supportive community, to examine the latest research on teaching and learning, and to conduct research on one's own teaching. The 2016-17 UNM Teaching Fellows program has focused on courses that have historically had high failure rates (over 25 percent).

\section{Out-of-classroom experiences}

Improvements to out-of-classroom experiences, area five, focused on changes to residence life, and career skill mapping, among other topics.

\section{Themed Residence Floors}

The Living Learning Program (LLP) promotes academic success among residential students. Nearly 1,000 programs are delivered each year to students living in UNM residences. Fifteen Living Learning Communities were created around areas of interest, such as "Engineering," "Outdoor Living \& Environmental Learners," and "Community Engagement." UNM is initiating a required on-campus living for first-year students in 2018.

\section{Career Skill Mapping}

To provide students with a better understanding of the purpose and impact of various in-class and out-of-classroom experiences, the Office of Career Services took on a project to map skills to core-curriculum Student Learning Outcomes. This project resulted in the UNM5, a set of five essential skills students learn throughout their time at UNM, including: 1. Communication, 2. Critical Thinking, 3. Collaboration, 4. Research and Assessment, and 5. Professionalism (these are further divided into five sub-skills per each overarching skill).

\section{Data Improvements}

Finally, in area six, a range of efforts focused on improving degree mapping, collection and more user-friendly web interfaces.

\section{Degree Plans}

The Degree Maps website (degrees.unm.edu) was developed in 2013 and provided student advisors with more accurate information about all UNM degrees. The site has been used effectively during orientation advising sessions, where advisors work with students to find programs. With only a few exceptions, all B.A. and B.S. degrees now require 120 student credit hours, with pathways to degrees visible on the site. The site students.unm.edu was developed to simplify student access to services and information.

\section{HIPs - Data Collection}

The FYSC Data Subcommittee studied freshman participation in high impact practices during the fall 2013 and spring 2014 semesters. Most of the 92 impact practices studied were cocurricular or student development interventions. Student participation data for each impact was collected manually, involving interviews and data requests of program coordinators and directors. The analysis also examined the impact of student participation at various levels (no engagement, low engagement, moderate engagement and high engagement). During the FoE self-study process in 2012, surveys of first-year students and faculty and staff were administered. A follow-up survey of first-year students was administered in Fall 2017. These survey results have guided recommendations and their implementation over the course of the effort. 


\section{Data and Assessment}

UNM bolstered its data collection and analysis systems, including updates to the Office of Institutional Analytics, and a new Institute for Design and Innovation. The result has included new tools for analyzing the structural complexity of curricular pathways to reduce bottlenecks, some early forays into cohort tracking, and comprehensive archiving of assessments so that they can be mined and analyzed more effectively. The overhaul of analytics required a substantial amount of effort to make raw data available, develop the tools and staff required to analyze it, and create easy-to-use visualizations for faculty, staff, and administrators.

\section{Take-Aways}

With its many initiatives, the project produced something of an emergent effect. The scale and cross-campus character created an environment within which many individuals on campus contributed and those contributions could flourish. Yet this scale resulted in such a large number of projects all coming to fruition at once that it was difficult to assess the impact of any single one. Projects that have proved difficult to evaluate, such as the Lobo Reading Experience, have also been difficult to sustain. The organization of the effort was large scale and required new methods and approaches for transcending organizational boundaries and allowing departments and offices to work together.

The collection of data on high impact practices yielded findings that can inform future work. First, students who were more successful in high school were more likely to be engaged in impact practices in college. Second, engaged students experienced significantly higher retention rates than unengaged students. Third, there was no significant difference in cumulative college GPA between engaged and unengaged students. Fourth, moderately engaged students were academically more successful than unengaged, minimally engaged and highly engaged students. Fifth, it appears that specific ethnic populations are more likely to participate in specific impact practices (for instance, Native American students are more likely to participate in mentoring programs, and less likely to participate in tutoring services). At the same time, the remarkable collective effort that yielded overall improvement in our graduation rates is difficult to break down into quantifiable measures.

The initiatives exerting the most impact were initiated by individual faculty members and small groups within departments and offices, with the assistance of a committee dedicated to working across a large university system to reduce barriers. Enterprising groups took on ambitious projects, and when they encountered resistance working across organizational lines, they relied on the support of an overarching committee with members overseeing widespread aspects of university governance to find and allocate resources, facilitate relationships across traditional university divisions, and relieve some of the administrative burden of locating resources, collecting data, and analyzing the effects of new ideas. Where innovative programs have been integrated into new or transformed units, from the Departments of English or Mathematics and Statistics, to CTL, to the Office of Advising Strategies, they have been the most sustainable.

Linking up improvement goals was a successful strategy. FoE worked hand in glove with the initiative to improve four-year graduation rates. The improvements in placement, developmental and introductory courses, greater integration of student support (especially advising), on the one hand, all fed into the creation of clear four-year (120-credit) degree pathways, on the other.

As a result of FoE, we are in a position to create faculty- and staff-driven integration of lowerdivision curriculum, beyond Freshman English and College-level Algebra, with student support resources. Faculty communities of practice, partnering with staff throughout Academic Affairs, 
are rethinking general education courses to incorporate into their classes community engaged learning, undergraduate research, race and social justice pedagogy and content, innovation, global awareness, and writing across the curriculum. FoE provided the opportunity for continued transformation of entry-level coursework by fostering greater awareness of how to calibrate efforts so that they serve both our neediest and our most academically prepared entering students. This work has already won support of a Lumina Foundation Grant for racial justice and equity.

The process used to collect student participation data and pair it with individual practices supported institutional change. Specifically, this process allowed for program staff to report data according to their programmatic definitions (for instance, 20 students participated in a professional conference), while allowing the professional intern to convert these easily to impact practice categories and definitions (for instance, 20 students participated in undergraduate research and career exploration). The project as a whole opened a path for analysis of outcomes for specific cohorts of first year students which will allow us to target support resources more effectively. It also revealed data gaps and some resistance to adoption of new digital tools.

Development of units with clearly defined goals resulted in long-term change. The consolidation of support for undergraduates, graduate students and faculty in a single Center for Teaching and Learning has created a more visible profile for learning support. The development of embedded advising and a central Office of Advising Strategies facilitates advising enhancement and assessment at an institution of our size. The creation of an Institute of Design \& Innovation (IDI) by the Office of Academic Affairs has improved UNM's ability to map curriculum and model flow towards degree in ways that may be of immediate use to other institutions.

Some of the faculty members most responsible for redesign of the first-year experience at UNM have received national recognition for their work. Sonia Gipson Rankin, former Associate Dean of University College and now a professor in the School of Law, received an "Outstanding FirstYear Student Advocate Award" and was invited to present at the annual conference of the awarding institution. The faculty members who designed and directed the innovative English Stretch and Studio program, Professors Bethany Davila and Cristyn Elder, were recognized at the annual Conference of College Composition and Communication. The program also resulted in a forthcoming publication, "Stretch and Studio Composition Practicum: Creating a Culture of Support and Success for Developing Writers at a Hispanic-Serving Institution." Under Dr. Aeron Haynie's direction, the Center for Academic Program Support (CAPS) earned certification as a Learning Center of Excellence (LCE) from the National College Learning Center Association (NCLCA), making UNM one of only four centers in the nation to receive this distinction.

At our flagship public institution where students of color represent the majority, we continue to measure and to experiment with FoE models. UNM's story features dedicated faculty and staff who, by tinkering with multiple initiatives, dramatically improve first-year outcomes. 